\title{
Preventing Breast, Cervical, and Colorectal Cancer Deaths: Assessing the Impact of Increased Screening
}

\author{
Krishna P. Sharma, $\mathrm{PhD}^{1}$; Scott D. Grosse, $\mathrm{PhD}^{2}$; Michael V. Maciosek, $\mathrm{PhD}^{3}$; Djenaba Joseph, MD, $\mathrm{MPH}^{1}$; \\ Kakoli Roy, $\mathrm{PhD}^{4}$; Lisa C. Richardson, MD, MPH${ }^{1}$; Harold Jaffe, $\mathrm{MD}^{5}$
}

\begin{abstract}
Accessible Version: www.cdc.gov/pcd/issues/2020/20_0039.htm
Suggested citation for this article: Sharma KP, Grosse SD, Maciosek MV, Joseph D, Roy K, Richardson LC, et al. Preventing Breast, Cervical, and Colorectal Cancer Deaths: Assessing the Impact of Increased Screening. Prev Chronic Dis 2020;17:200039. DOI: https://doi.org/10.5888/pcd17.200039.
\end{abstract}

\section{PEER REVIEWED}

\section{Summary}

What is already known on this topic?

Screening for colorectal cancer and for female breast and cervical cancers can effectively reduce deaths from these cancers. Yet many preventive services, including cancer screening, remain underutilized in the United States.

\section{What is added by this report?}

Increased use of screening from current levels to $100 \%$ would prevent an additional 2,821 deaths from breast cancer, 6,834 deaths from cervical cancer, and 35,530 deaths from colorectal cancer over a lifetime of the respective single-year cohort. Increasing use of colorectal cancer screening would prevent more deaths than an equivalent increase in breast and cervical cancer screening.

What are the implications for public health practice?

Public health programs incorporating strategies shown to be effective can help increase screening rates. Organized screening approaches leveraging partnerships between public health and primary health care to implement such strategies could be used to reduce the prevalence of these cancers.

\section{Abstract}

\section{Introduction}

The US Preventive Services Task Force (USPSTF) recommends select preventive clinical services, including cancer screening. However, screening for cancers remains underutilized in the United States. The Centers for Disease Control and Prevention leads initiatives to increase breast, cervical, and colorectal cancer (CRC) screening. We assessed the number of avoidable deaths from increased screening, according to USPSTF recommendations, for CRC and female breast and cervical cancers.

\section{Methods}

We used model-based estimates of avoidable deaths for the lifetime of single-year age cohorts under the current and increased use of screening scenarios (data year 2016; analysis, 2018). We calculated prevented cancer deaths for each $1 \%$ increase in screening uptake and extrapolated to current level of screening (2016), current level plus 10 percentage points, and increasing screening to $90 \%$ and $100 \%$ of the eligible population.

\section{Results}

Increased use of screening from current levels to $100 \%$ would prevent an additional 2,821 deaths from breast cancer, 6,834 deaths from cervical cancer, and 35,530 deaths from CRC over a lifetime of the respective single-year cohort. Increasing use of CRC screening would prevent approximately 8.5 times as many deaths as the equivalent increase in use of breast cancer screening (women only), although twice as many people (men and women) would have to be screened for CRC.

\section{Conclusions}

A large number of deaths could be avoided by increasing breast, cervical, and CRC screening. Public health programs incorporating strategies shown to be effective can help increase screening rates.

\section{Introduction}

The US Preventive Services Task Force (USPSTF) recommends select clinical preventive services with "A" and "B" recommendation grades for the eligible population. A grade "A" recommendation reflects high certainty of substantial net benefit from a ser- 
vice; grade "B" reflects high certainty of moderate benefit or moderate certainty of substantial benefit. USPSTF recommendations include routine screening for female breast cancer in women aged 50 to 74 years, cervical cancer in women aged 21 to 65 years, and colorectal cancer (CRC) in men and women aged 50 to 75 years (1). Most private health plans cover these services without copays or deductibles. However, insurance coverage does not ensure uptake of recommended services, and many preventive services remain underutilized (2).

To increase the use of these services, the US Department of Health and Human Services supports various programs and initiatives (3). For example, 2 cancer control programs at the Centers for Disease Control and Prevention (CDC), the National Breast and Cervical Cancer Early Detection Program (NBCCEDP) and the Colorectal Cancer Control Program (CRCCP), seek to increase screening use among low-income, medically underserved populations $(4,5)$. Despite the availability of screening services and better treatment outcomes, a large number of patients still die of these cancers. In 2016, the number of deaths from female breast cancer was 41,487; from cervical cancer, 4,188; and from CRC, 52,286 (6). In 2016, the self-reported screening rates for female breast and cervical cancers were $78.3 \%$ and $79.9 \%$, respectively, and the self-reported screening rate for $\mathrm{CRC}$ was $67.7 \%$ (7).

In this article, we assess the number of potential deaths that could be prevented by increasing screening for female breast and cervical cancers and for CRC according to USPSTF recommendations. The report is motivated by the need to increase the use of evidence-based interventions that reduce the rates of illness and death from cancer.

\section{Methods}

We simulated and compared the number of deaths that could be prevented by increasing screening from current rates to defined targets by using previously reported model-based estimates. We compared the cumulative numbers of cancer deaths for a singleyear age cohort under different scenarios: current level of screening (2016), current level plus 10 percentage points, and increasing screening to $90 \%$ and $100 \%$ of the eligible population. We also calculated the numbers of adults currently screened and expected to be screened under different scenarios of increased screening. Table 1 provides a summary of key analysis assumptions and model inputs. Current screening estimates are based on 2016 survey data from the Behavioral Risk Factor Surveillance System (BRFSS) (7).

Each of the simulation models on which our calculations are based followed a synthetic cohort from the USPSTF-recommended starting age of screening: 50-year-old women for breast cancer screen- ing, 21-year-old women for cervical cancer screening, and 50year-old men and women for CRC screening. The simulations followed each cohort through their lifetimes. Screening modalities included mammography for breast cancer and cytology or Pap test for cervical cancer. For CRC, the model assumed a mix of annual fecal occult blood test (FOBT), flexible sigmoidoscopy every 5 years plus FOBT every 3 years, or colonoscopy every 10 years (Table 1).

The estimates of avoidable burden were prepared in 2018 by Health Partners Institute researchers using models that were previously used in peer-reviewed studies to inform the National Commission on Prevention Priorities (NCPP) ranking of clinical preventive services (8). Specifically, the estimates for avoidable deaths from breast cancer screening (9) were based on results of 5 Cancer Information Surveillance Modeling Network screening models (10) plus an estimate from a sixth model (11). Estimates for cervical cancer screening and CRC screening were based on results from models to inform the same NCPP ranking $(12,13)$. These reports provide estimates of cancer deaths that would be prevented either by screening $100 \%$ of the target population compared with no screening $(8,9)$ or by screening a portion of the target population who would accept and follow up with screening if recommended by a physician $(10,11,14)$. Each model estimated cancer deaths prevented by first constructing a natural history of cancer based on progression of lesions through cancer stages and then simulating the potential for screening to interrupt cancer progression and prevent death. Using the estimates from models, we calculated the deaths prevented from each $1 \%$ increase in screening uptake in the US eligible population and linearly scaled that estimate from current screening rates up to the screening rates in the scenarios just described. Linear extrapolation should provide a reasonable estimate of the impact of increasing screening rates when capacity exists or is developed to provide additional screening and follow-up of quality equal to existing screening and follow-up, and when the currently screened and unscreened populations have similar risks of lesion development and cancer progression.

\section{Results}

If the current level of screening use were maintained, 10,179 deaths from breast cancer would be prevented among the cohort of 50 -year-old women over their lifetime; 27,166 deaths from cervical cancer would be prevented among the cohort of 21-year-old women; and 74,470 deaths from CRC would be prevented among the cohort of 50-year-old men and women (Table 2).

Using a linear relation between screening use and avoided deaths indicated a similar pattern of relative incremental deaths preven-

The opinions expressed by authors contributing to this journal do not necessarily reflect the opinions of the U.S. Department of Health and Human Services, the Public Health Service, the Centers for Disease Control and Prevention, or the authors' affiliated institutions. 
ted through increased screening. Increases of 10 percentage points would prevent an additional 1,300 deaths from breast cancer; 3,400 deaths from cervical cancer; and 11,000 deaths from CRC over the lifetime of each cohort. In terms of the 2016 general population, those reductions would require additional screenings of 4.9 million women for breast cancer, 9.7 million women for cervical cancer, and 9.6 million men and women for CRC (Table 1).

The impact of increasing the screening rate to $100 \%$ sets the upper limit on the number of potentially avoidable deaths (Figure). Screening of $100 \%$ age-appropriate adults could prevent 2,821 additional deaths from breast cancer over the lifetime of a cohort of 50-year-old women; 6,834 additional deaths from cervical cancer over the lifetime of 21-year-old women; and 35,530 additional deaths from CRC over the lifetime of 50-year-old men and women. Increasing use of CRC screening would prevent approximately 8.5 times as many deaths as the equivalent increase in use of breast cancer screening (women only), although twice as many people (men and women) would have to be screened for CRC (Table 1).

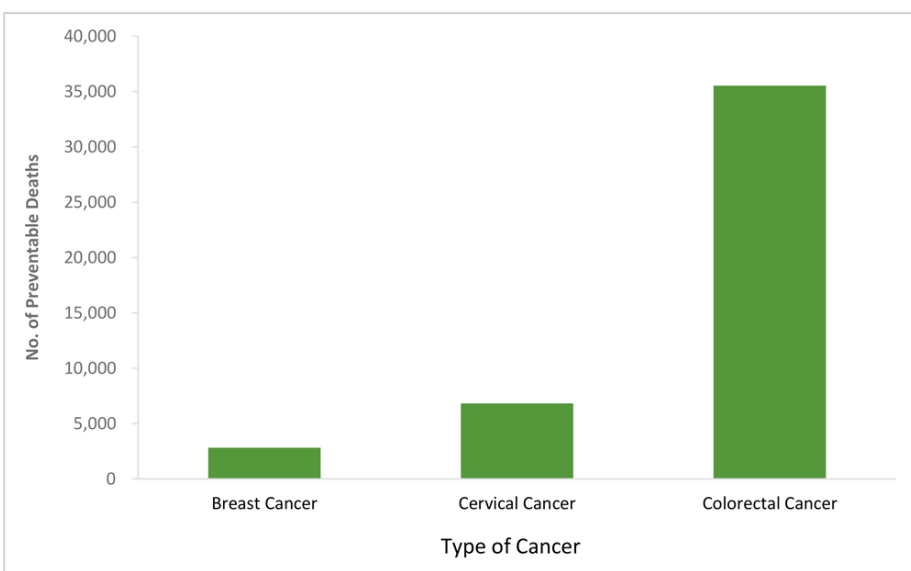

Figure. Estimates of maximum number of preventable deaths in a single-year cohort with increased use of screening under US Preventive Services Task Force guidelines (study year 2018). Preventable deaths over a lifetime for breast cancer are among women aged 50, for cervical cancer among women aged 21, and for colorectal cancer among men and women aged 50.

\section{Discussion}

The estimated deaths from breast cancer, cervical cancer, and CRC prevented under different scenarios, comparing the impact of incremental screening rates, may be useful for setting goals and making resource allocation decisions on prevention. For example, one of the goals of Healthy People 2020, the US government's 10year national health objectives, is to reduce female breast and cervical cancer mortality by $10 \%$ and CRC mortality by $15 \%(15)$.
Our estimates suggest that large numbers of deaths from cancer could be prevented through increased use of evidence-based screenings. The greatest impact could be realized for increased CRC screening. The magnitude of potential impact of universal $\mathrm{CRC}$ screening is attributed to the fact that $\mathrm{CRC}$ screening has a current rate that is lower than breast and cervical cancer screening, includes both men and women, and has a larger proportionate decrease in mortality associated with it. Although we recognize that $100 \%$ screening is not an achievable goal, we included it as a target to illustrate the maximum benefit that could be achieved by increased screening.

The Community Preventive Services Task Force (CPSTF) recommends evidence-based strategies, such as patient and provider reminders, to increase screening rates for all 3 cancers (16-18). CDC's CRCCP aims to increase screening rates among priority populations through implementation of these strategies in health system clinic settings. The NBCCEDP is a long-standing CDC initiative that screened over 1.4 million low-income, uninsured and underinsured women over the 5 years ending in 2017 alone (19). These public health programs, along with other state and local efforts, are critical to increasing cancer screening. For example, early results of CRCCP suggested a 4.4 percentage-point annual increase in screening rates among the participating clinics (5). By the second and third year of the CRCCP, the rate increased by 8.3 and 10.1 percentage points, respectively. An increase of 10.1 percentage points implied more than 82,000 additional CRC screenings under CRCCP (20).

Increasing cancer screening rates would require additional resources for the delivery of clinical services, as well as strategies to promote uptake of screening in population groups with lower use of screening. Previous studies that examined the cost of public provision of programs to increase screening found that such programs include not only cost of screening services but also substantial cost of administering and promoting the programs $(21,22)$. The incremental costs associated with additional screenings may be offset by early detection of cancer or precancerous abnormalities through routine screening. In particular, use of colonoscopy for CRC screening or as follow-up to abnormal fecal screening can significantly reduce the onset of CRC through removal of precancerous polyps in addition to allowing early detection of tumors. Consequently, economic analyses have concluded that screening for CRC might be cost-saving to health care systems, with the magnitude of cost savings greater for colonoscopy-based screening $(23,24)$. A CPSTF systematic review found that multicomponent interventions to promote CRC might also be cost-saving, a finding that was based on a small study in a disadvantaged population in south Texas and a modeling study from South Korea (25).

The opinions expressed by authors contributing to this journal do not necessarily reflect the opinions of the U.S. Department of Health and Human Services, the Public Health Service, the Centers for Disease Control and Prevention, or the authors' affiliated institutions. 
However, those analyses did not factor in competing risks or future medical costs, although taking those into account may still render CRC screening to be considered cost-effective even if not cost-saving (26).

Our estimates of the relative contributions of recommended screenings align with previous estimates, although methods differ (27). In particular, the results of Farley et al reflect annual impact in a US cross-section, while our estimates reflect the lifetimes of a US birth cohort. These different methods could produce the same number of life-years at risk of cancer and the same results if, among other things, the successive birth cohorts represented in the cross-section were all the same size. However, because the older cohorts in a cross-section came from smaller, pre-1946 birth cohorts, annual estimates tend to be smaller than lifetime estimates from a birth cohort. Our estimate of $68 \%(35,530)$ CRC deaths prevented, associated with increasing screening from $68 \%$ to $100 \%$, is higher than the Meester et al estimate (28) of 58\% CRC deaths prevented in 2020 , even with an increase in screening rate from $60 \%$ to $100 \%$.

\section{Limitations}

The current rates of screening used in this study were based on self-reported BRFSS survey data, but actual rates could be substantially less. Past studies have suggested that self-reports of screening overestimated screening rates by as much as 15 to 25 percentage points $(29,30)$. We did not account for the potential contribution from the use of human papillomavirus (HPV) vaccination to reduce incidence of cervical cancer; neither did we include HPV testing for cervical cancer screening in women aged 30 or older. The estimates for CRC deaths prevented were based on 3 screening strategies: FOBT alone, flexible sigmoidoscopy combined with FOBT, and colonoscopy alone; other currently available or recommended strategies or test methods (eg, fecal immunochemical test, fecal DNA, Cologuard) were not included. Furthermore, our approach assumes proportional effects of screening and does not account for population heterogeneity in screening frequencies and risk of death. Also, the validity of our approach to extrapolate outside the observed range of data is not known, although this is often the only approach available.

\section{Conclusions}

Increasing screening for CRC and breast and cervical cancers could prevent a substantial number of deaths attributed to these cancers. Organized screening approaches that leverage partnerships between public health and primary health care to implement evidence-based strategies could be used to reduce the prevalence of these cancers.

\section{Acknowledgments}

The authors thank Martin Meltzer and Phoebe Thorpe for their contributions. No financial disclosures were reported by the authors of this article, and no external financial support was received for this work. No copyrighted instruments or tools were used for this study. The findings and conclusions in this report are those of the authors and do not necessarily represent the official position of CDC.

\section{Author Information}

Corresponding Author: Krishna P. Sharma, PhD, Division of Cancer Prevention and Control, National Center for Chronic Disease Prevention and Health Promotion, Centers for Disease Control and Prevention, 4770 Buford Highway, MS-MF76, Atlanta, GA 30341. Telephone: 404-498-1530. Email: ksharma@cdc.gov.

Author Affiliations: ${ }^{1}$ Division of Cancer Prevention and Control, National Center for Chronic Disease Prevention and Health Promotion, Centers for Disease Control and Prevention, Atlanta, Georgia. ${ }^{2}$ National Center on Birth Defects and Developmental Disabilities, Centers for Disease Control and Prevention, Atlanta, Georgia. ${ }^{3}$ HealthPartners Institute, Minneapolis, Minnesota. ${ }^{4}$ National Center for Chronic Disease Prevention and Health Promotion, Centers for Disease Control and Prevention, Atlanta, Georgia. ${ }^{5}$ Office of the Associate Director for Science, Centers for Disease Control and Prevention, Atlanta, Georgia.

\section{References}

1. US Preventive Services Task Force. The guide to clinical preventive services 2014: recommendations of the US Preventive Services Task Force. Agency for Healthcare Research and Quality; 2014.

2. Han X, Robin Yabroff K, Guy GP Jr, Zheng Z, Jemal A. Has recommended preventive service use increased after elimination of cost-sharing as part of the Affordable Care Act in the United States? Prev Med 2015;78:85-91.

3. US Department of Health and Human Services. Prevention and Public Health Fund; 2016. https://www.hhs.gov/open/ prevention/index.html. Accessed July 7, 2020.

4. Miller JW, Plescia M, Ekwueme DU. Public health national approach to reducing breast and cervical cancer disparities. Cancer 2014;120(Suppl 16):2537-9.

\footnotetext{
The opinions expressed by authors contributing to this journal do not necessarily reflect the opinions of the U.S. Department of Health and Human Services, the Public Health Service, the Centers for Disease Control and Prevention, or the authors' affiliated institutions.
} 
5. DeGroff A, Sharma K, Satsangi A, Kenney K, Joseph D, Ross $\mathrm{K}$, et al. Increasing colorectal cancer screening in health care systems using evidence-based interventions. Prev Chronic Dis 2018;15:180029.

6. Centers for Disease Control and Prevention. US Cancer Statistics Data Visualizations Tool. https:/gis.cdc.gov/Cancer/ USCS/DataViz.html. Accessed July 7, 2020.

7. BRFSS Prevalence and Trends Data, BRFSS Web Enabled Analysis Tool — 2016. https://nccd.cdc.gov/weat/\#/analysis. Accessed July 7, 2020.

8. Maciosek MV, LaFrance AB, Dehmer SP, McGree DA, Flottemesch TJ, Xu Z, et al. Updated priorities among effective clinical preventive services. Ann Fam Med 2017;15(1):14-22.

9. Maciosek MV, LaFrance A. Breast Cancer Screening. https:// www.healthpartners.com/institute/wp-content/uploads/2018/ 07/Breast-Cancer-Screening-2018-02-06.pdf. Accessed July 7, 2020.

10. Stout NK, Lee SJ, Schechter CB, Kerlikowske K, Alagoz O, Berry D, et al. Benefits, harms, and costs for breast cancer screening after US implementation of digital mammography. J Natl Cancer Inst 2014;106(6):dju092.

11. Schousboe JT, Kerlikowske K, Loh A, Cummings SR. Personalizing mammography by breast density and other risk factors for breast cancer: analysis of health benefits and costeffectiveness. Ann Intern Med 2011;155(1):10-20.

12. Flottemesch TJ, Maciosek MV, Edwards NM, LaFrance AB. Impact of offering cervical cancer screening and HPV vaccination against types 16 and 18 on cervical cancer; 2016. https://www.healthpartners.com/ucm/groups/public/@hp/ @public/@institute/documents/documents/entry_189222.pdf. Accessed July 7, 2020.

13. Flottemesch TJ, Maciosek MV, Edwards NM, LaFrance AB. Impact of offering colorectal cancer screening; 2016. https:// www.healthpartners.com/ucm/groups/public/@hp/@public/ @institute/documents/documents/entry_189224.pdf. Accessed July 7, 2020.

14. Maciosek MV, Edwards NM, Davis MK, Khanchandani HS, Butani AL, McGree DA, et al.Breast cancer screening: technical report prepared for the National Commission on Prevention Priorities; 2006. http://prevent.org/images/stories/ clinicalprevention/breastcancer.pdf. Accessed July 7, 2020.

15. US Department of Health and Human Services. Healthy people 2020: topics and objectives - cancer. https:// www.healthypeople.gov/2020/topics-objectives/topic/cancer. Accessed July 7, 2020.

16. Final update summary: cervical cancer screening. Rockville (MD): US Preventive Services Task Force; 2016.

17. Final update summary: breast cancer screening. Rockville (MD): US Preventive Services Task Force; 2018.
18. Final update summary: colorectal cancer screening. Rockville (MD): US Preventive Services Task Force; 2018.

19. Centers for Disease Control and Prevention, National Breast and Cervical Cancer Early Detection Program. Five-year summary: July 2012 to June 2017. https://www.cdc.gov/ cancer/nbccedp/data/summaries/index.htm. Accessed July 7 , 2020.

20. Centers for Disease Control and Prevention, Colorectal Cancer Control Program. Spotlight on year 3. https://www.cdc.gov/ cancer/crccp/year3.htm. Accessed July 7, 2020.

21. Ekwueme DU, Subramanian S, Trogdon JG, Miller JW, Royalty JE, Li C, et al. Cost of services provided by the National Breast and Cervical Cancer Early Detection Program. Cancer 2014;120(Suppl 16):2604-11.

22. Subramanian S, Tangka FKL, Hoover S, Royalty J, DeGroff A, Joseph D. Costs of colorectal cancer screening provision in CDC's Colorectal Cancer Control Program: Comparisons of colonoscopy and FOBT/FIT based screening. Eval Program Plann 2017;62:73-80.

23. Ran T, Cheng C-Y, Misselwitz B, Brenner H, Ubels J, Schlander MJ, et al.Cost-effectiveness of colorectal cancer screening strategies - a systematic review. Clin Gastroenterol Hepatol 2019;17(10):1969-81.

24. Heavener T, McStay FW, Jaeger V, Stephenson K, Sager L, Sing J. Assessing adherence and cost-benefit of colorectal cancer screening for accountable providers. Proc Bayl Univ Med Cent 2019;32(4):490-7.

25. Mohan G, Chattopadhyay SK, Ekwueme DU, Sabatino SA, Okasako-Schmucker DL, Peng Y, et al.; Community Preventive Services Task Force. Economics of multicomponent interventions to increase breast, cervical, and colorectal cancer screening: a Community Guide systematic review. Am J Prev Med 2019;57(4):557-67.

26. Ratushnyak S, Hoogendoorn M, van Baal PHM. Costeffectiveness of cancer screening: health and costs in life years gained. Am J Prev Med 2019;57(6):792-9.

27. Farley TA, Dalal MA, Mostashari F, Frieden TR. Deaths preventable in the U.S. by improvements in use of clinical preventive services. Am J Prev Med 2010;38(6):600-9.

28. Meester RG, Doubeni CA, Zauber AG, Goede SL, Levin TR, Corley DA, et al. Public health impact of achieving $80 \%$ colorectal cancer screening rates in the United States by 2018. Cancer 2015;121(13):2281-5.

29. Cronin KA, Miglioretti DL, Krapcho M, Yu B, Geller BM, Carney PA, et al. Bias associated with self-report of prior screening mammography. Cancer Epidemiol Biomarkers Prev 2009;18(6):1699-705.

30. Rauscher GH, Johnson TP, Cho YI, Walk JA. Accuracy of self-reported cancer-screening histories: a meta-analysis. Cancer Epidemiol Biomarkers Prev 2008;17(4):748-57.

The opinions expressed by authors contributing to this journal do not necessarily reflect the opinions of the U.S. Department of Health and Human Services, the Public Health Service, the Centers for Disease Control and Prevention, or the authors' affiliated institutions. 


\section{Tables}

Table 1. Summary of Key Analysis Assumptions Used to Estimate the Effects of Colorectal Cancer and Women's Breast and Cervical Cancers in the United States

\begin{tabular}{|c|c|c|c|}
\hline Analysis Assumption & Breast Cancer & Cervical Cancer & Colorectal Cancer \\
\hline Study cohort & 50-year-old women & 21-year-old women & 50-year-old men and women \\
\hline Screening age ${ }^{a}$ & $50-74$ y & $21-65 y$ & $50-75 y$ \\
\hline Eligible US population for the test (million) ${ }^{b}$ & 48.7 & 96.7 & 95.9 \\
\hline Follow-up period & \multicolumn{3}{|c|}{ Lifetime or until death by any cause } \\
\hline Screening tests included ${ }^{a}$ & Mammogram & Cytology or pap smear & $\begin{array}{l}\text { High-sensitivity FOBT, flexible sigmoidoscopy, or } \\
\text { colonoscopy }\end{array}$ \\
\hline Screening intervals ${ }^{a}$ & Every 2 years & Every 3 years & $\begin{array}{l}\text { Annual screening with high-sensitivity FOBT } \\
\text { Sigmoidoscopy every } 5 \text { years, with high-sensitivity } \\
\text { FOBT every } 3 \text { years } \\
\text { Screening colonoscopy every } 10 \text { years }\end{array}$ \\
\hline Baseline screening rate $(\%)^{c}$ & 78.3 & 79.9 & 67.7 \\
\hline $\begin{array}{l}\text { Age eligible US population screened in baseline } \\
\text { (millions) }\end{array}$ & 37.4 & 76.8 & 63.5 \\
\hline $\begin{array}{l}\text { Other screening scenarios (number of additional } \\
\text { people needed to be screened to reach the goal [in } \\
\text { millions] by cancer type } \text { b }^{\text {) }}\end{array}$ & \multicolumn{3}{|c|}{$\begin{array}{l}\text { Increase in baseline rate by } 10 \text { percentage points (breast, 4.8; cervical, 9.6; colorectal, 9.4) } \\
\text { Screening rate of } 90 \% \text { (breast, 5.6; cervical, 9.7; colorectal, 20.9) } \\
\text { Screening rate of } 100 \% \text { (breast, 10.4; cervical, 19.3; colorectal, 30.3) }\end{array}$} \\
\hline
\end{tabular}

Abbreviations: BRFSS, Behavioral Risk Factor Surveillance System; FOBT, fecal occult blood test.

${ }^{a}$ Based on US Preventive Services Task Force recommendations, 2008.

${ }^{\mathrm{b}}$ Author calculations based on annual estimates of the resident population by sex, race, and Hispanic origin for 2016 from the US Census.

${ }^{\mathrm{c}}$ Based on BRFSS 2016 data (7).

The opinions expressed by authors contributing to this journal do not necessarily reflect the opinions of the U.S. Department of Health and Human Services, the Public Health Service, the Centers for Disease Control and Prevention, or the authors' affiliated institutions. 
Table 2. Estimates of Current and Increased Use of US Preventive Services Task Force-Recommended Cancer Screenings Over the Lifetime of Study Cohort, United States, 2018

\begin{tabular}{|c|c|c|c|c|}
\hline \multirow[b]{2}{*}{ Preventive Service } & \multirow[b]{2}{*}{$\begin{array}{l}\text { Current } \\
\text { Use, } \%^{a}\end{array}$} & \multirow[b]{2}{*}{$\begin{array}{c}\text { Current Impact } \\
\text { (Deaths Prevented) }\end{array}$} & \multicolumn{2}{|c|}{$\begin{array}{l}\text { Incremental Impact (Deaths Prevented) With } \\
\text { Increased Screening }\end{array}$} \\
\hline & & & $\begin{array}{l}\text { Increase Screening by } 10 \\
\text { Percentage Points }\end{array}$ & $\begin{array}{l}\text { Increase Screening to } \\
90 \%\end{array}$ \\
\hline Breast cancer screening of 50-year-old women until the age of 74 & 78.3 & 10,179 & 1,300 & 1,521 \\
\hline Cervical cancer screening of 21-year-old women until the age of 65 & 79.9 & 27,166 & 3,400 & 3,434 \\
\hline Colorectal cancer screening of 50-year-old adults until the age of 75 & 67.7 & 74,470 & 11,000 & 24,530 \\
\hline
\end{tabular}

a Source: Behavioral Risk Factor Surveillance System Prevalence and Trends Data (7).

${ }^{\mathrm{b}}$ Model-based estimates by authors. 